\title{
Is there a difference in job satisfaction at emergency medicine service (EMS) team and EMS dispatchers?
}

R.M. Ujevic, J.Prizmic, A.Belak Barisin, M. Maras, L.Luetic, Institute for Emergency Medicine Split-Dalmatian County, Croatia

INTRODUCTION: The aim of this study is to determine job satisfaction among personnel of Institute of Emergency Medical Service Split - Dalmatian County in Split. Daily in Split three Team 1 ( T1 - physician, emergency medicine technician -EMT, driver with no former medical education) and Team 2 ( T2 - two EMT) during 24 hours, take care of 178000 inhabitants. Their activities are directed by Medical Dispatch Unit - both for Split and whole County with 455000 inhabitants.

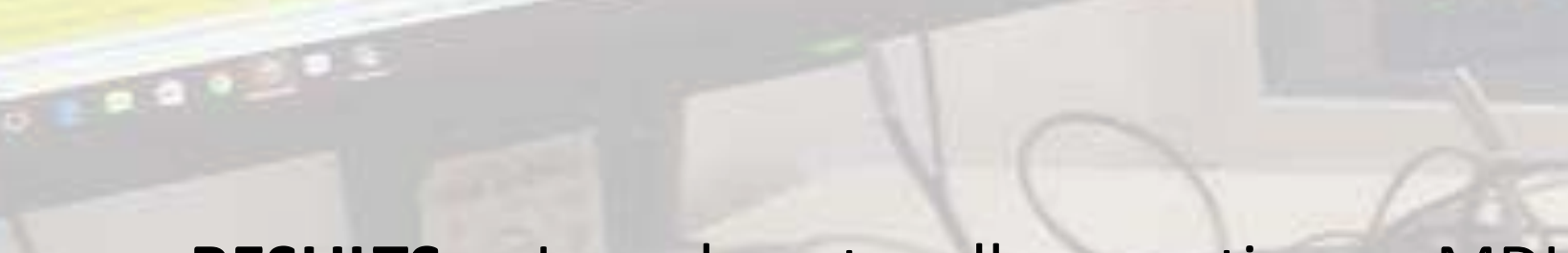

RESULTS: In almost all questions MDU personnel showed better satisfaction ( $p>0,05$ no significant). The only question where EMS teams showed better satisfaction was about praise, acknowledgment for well done job average 2,7 to 2,6 at MDU, though the both scores are more in less satisfied than in neutral opinion. The lowest score in EMS group was 2,5 (SD 1,19) (possibility of advancing), and in MDU group 2,4 (SD 1,01)( working conditions) The general job satisfaction was 3,5 ( SD 0,96) in EMS group and 3,6 ( SD 0,76) in MDU group. The highest score 4,2 in EMS was about variety and in MDU group 4,8 about safety of steady employment. Intrinsic components have achieved better score at both groups.
METHODS: We made a cross - sectional study with 51 participants - 37 EMS provider teams and 14 employees of MDU. They fulfilled validated Minnesota job satisfaction questionnaire with 21 question, also answering about years working in EMS. Answers were offered according to Likert scale from 1 to 5 . Arithmetic mean and standard deviation was calculated for each question in both categories.

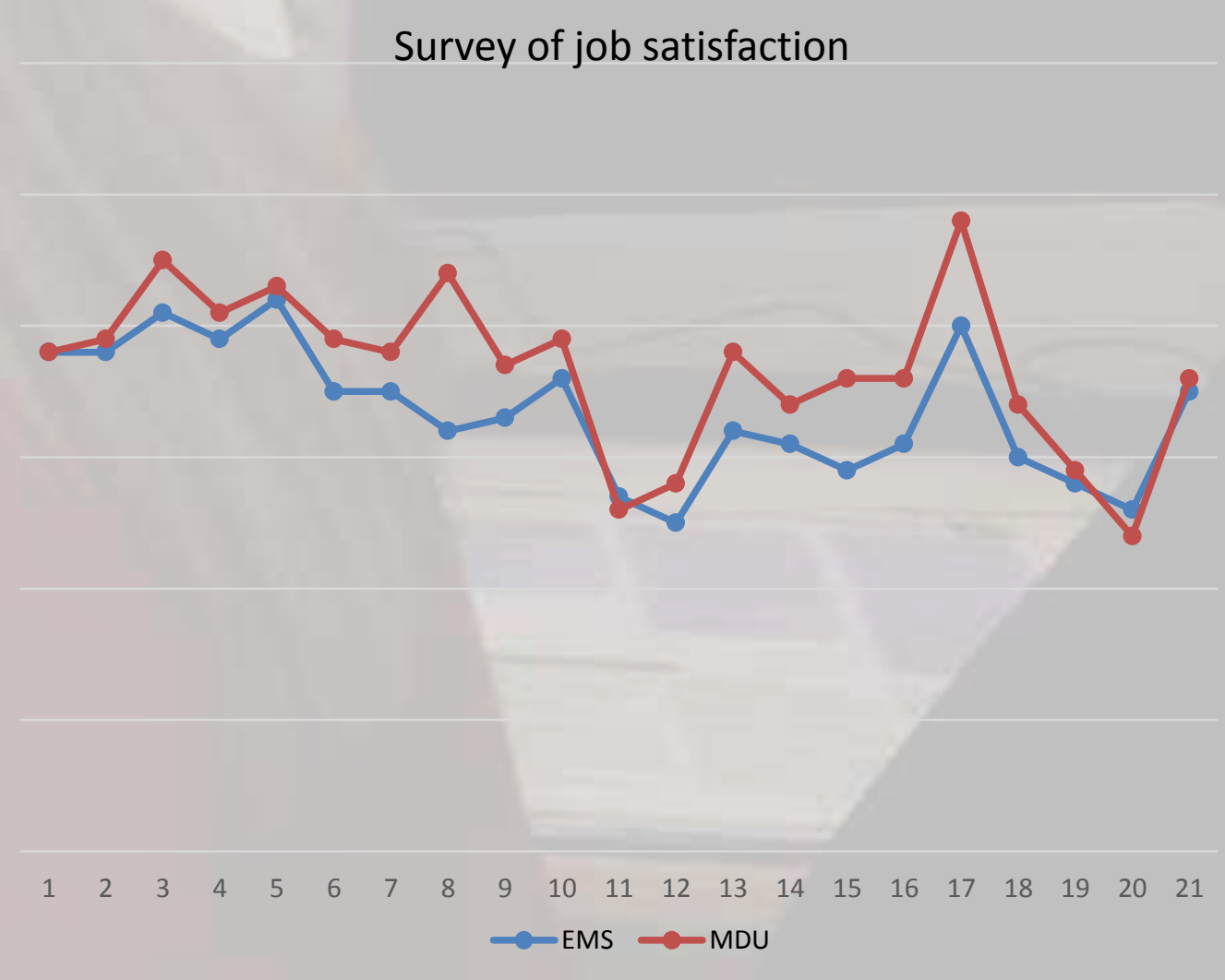

CONCLUSION: MDU personnel has better job satisfaction than EMS teams working in field. Improving working conditions and communication might improve job satisfaction in both groups. 